\title{
Anti-Fat Attitudes of African American Preschool Children: An Exploratory Study
}

\author{
Nathanael G. Mitchell ${ }^{1, *}$, Danelle Stevens- Watkins ${ }^{2}$, Alexandra W. Bea ${ }^{1}$ \\ ${ }^{1}$ School of Professional Psychology,Spalding University,845 South 3rd St.,Louisville, KY 40203 \\ ${ }^{2}$ College of Educational, School, \& Counseling Psychology,University of Kentucky, Lexington, KY, 40506 \\ *Corresponding Author: nmitchell01@spalding.edu
}

Copyright (C) 2014 Horizon Research Publishing All rights reserved.

\begin{abstract}
Negative attitudes towards obesity are nearly ubiquitous in western society, with measurable anti-fat attitudes in children even as young as three years of age. Unfortunately, the research on the anti-fat attitudes in preschool children has used primarily white, middle class children as their participants. This is a significant limitation as previous research indicates that minority children are at greater risk of obesity and that African American individuals may have greater acceptance of a larger body size.The goal of the current study was to investigate the extent to which young African American preschool children harbor anti-fat attitudes toward obese body types. 24 African American preschool children were asked to assign both positive and negative attributes to pictures of three different body sizes (thin, average, obese). Results indicated that preschool children aged 4 and 5 attribute more negative characteristics to obese body figures than to either thin or average, while 3 -year $=$ old African American children do not. Children's BMI was not a significant correlate of anti-fat attitudes. Findings further research by showing that not only Caucasian children harbor anti-fat attitudes, but also young African American children harbor measureable negative attitudes towards obesity by age 4 .
\end{abstract}

Keywords Anti-fat, African American, Weight Bias, Preschool

\section{Introduction}

Obesity has quickly become one of the nation's most prominent health concerns. The American Medical Association's most recent results from the National Health and Nutrition Examination Survey (NHANES) suggest that between 2009 and 2010, overall obesity prevalence rests at $35.5 \%$ among men and $35.8 \%$ among women [1]. The rate at which obesity continues to ravage the country's health is worthy of considerable attention, particularly when considering the impact within minority populations. While obesity prevalence among adults is staggering, obesity is the most prevalent nutritional disease of American children and adolescents [2]. Despite the overall surge in childhood obesity, the prevalence of obesity among minority children is perpetually higher [1]. Specifically, racial disparities among preschool children have been shown to exist [3] and the severity of obesity prevalence, particularly among African American girls is increasing [4].

Regardless of the increasing predominance of obesity in western society and within social class groups, research indicates that society holds negative attitudes and biases toward obese individuals [5]. Obese individuals are often labeled as lazy, less competent and lacking in self-discipline as opposed to their thin or normal weight counterparts [6] with society tending to view obesity as a result of causes within one's own personal control [7] Surprisingly, both obese and normal weight individuals express an equal amount of distaste for those who are overweight or obese providing little in-group protection from discriminatory attitudes $[8,5]$. Furthermore, weight bias and discrimination closely resembles that of racial discrimination, with obese individuals often experiencing higher rates of interpersonal mistreatment above and beyond that of discrimination due to race or gender [9].

Even more concerning, obesity discrimination is largely considered to be more socially acceptable than other forms of discrimination and stigma, such as racism or heterosexism [10]. Overwhelmingly, obesity is viewed culturally as the result of self-indulgence [11,12]. With this in mind, the notion that self-gratification exists as the causal link for obesity largely informs the development of an anti-fat bias [6]. Theoretically, the attributes to which we assign to obese individuals influences the nature and degree of discrimination. In this context, attribution theory aids in the conceptualization of the formation of anti-fat bias and subsequent discriminatory attitudes and behaviors [13]. These attributional beliefs, consisting of casual links and responsibility combined, both lead to obesity bias $[14,15]$, particularly when obesity is viewed by others as a highly controllable disease [16].

Obesity biases have been observed institutionally among teachers [17], employers [18], nurses [19], physician 
assistants [20], physical educators [21], medical students [22] and even among physicians, pharmacologists and psychologists who specialize in treating obese patients [23] indicating the ubiquitous nature of anti-fat attitudes. Discriminatory and biased attitudes of professionals often lead to less than desirable consequences within the institutions in which they preside. Obese individuals are considerably less likely to be offered an interview for an occupational position, receive a promotion at work, obtain quality health services or receive adequate health insurance coverage $[17,12]$. With such pervasive and discriminatory attitudes and behaviors at play, individuals who are obese are considerably more likely to suffer from taxing mental and physical conditions due to these discriminatory messages [24]. In addition, obese women have been found to experience more depressive episodes, have higher rates of suicidal ideation and make more suicide attempts [25] indicating the crucial need for the continued investigation into obesity stigma and bias.

Unfortunately, negative attitudes and biases are evident among younger members of our society $[26,27,28]$ with measurable stigmatization of obesity in children even as young as three years of age $[29,30]$. As with adults, social stigmatization and maltreatment related to obesity has the potential to leave lasting effects on children that extend to their mental and physical wellbeing [31]. Often beginning with teasing and name-calling as children [32], overweight adolescents are more likely to become socially isolated, particularly if they are of lower socioeconomic status (Hanson, [33], exacerbating the emotional toll already placed on obese individuals [34].

Unfortunately, the research on the stigmatization of obesity in preschool children has used primarily white, middle class children as their participants $[30,35,36]$. The lack of established research in this realm is concerning, as African Americans overall tend to be under-represented in the literature $[37,38,39]$. This degree of under-representation could lead to the dismissal of potential racial influences that may perhaps account for disparities among racial groups, particularly when studying bias. As such, there is little attention in current literature as to whether or not the stigmatization of obese individuals is present in very young African American children from economically disadvantaged backgrounds. Interestingly, previous work has found that African American individuals tend to exhibit greater acceptance for larger body figures $[40,41,42]$. These findings further reinforce the need for the examination of bias in this regard as the experience of African American children may be largely different than that of white children. Investigation into this area of study is crucial to begin to identify biases among these children, develop strategies to target the devastating consequences of obesity stigma and to prevent further victimization [43]. The goal of the exploratory study was to investigate the extent to which young African American children harbor anti-fat attitudes toward obese body types of similar aged children and ethnicity.

\section{Methods}

\subsection{Participants}

The current sample consisted of 23 African-American preschool aged children (ages 3-5) in an urban district of a medium sized city in the Midwest. Selection of participants was based on their participation in a larger psycho-educational program designed to increase children's participation in physical activity and improve nutritional knowledge.

\subsection{Instruments \& Procedure}

\subsubsection{Body Figure Drawings.}

Participants were shown figures of children who were thin, average, or obese. These figures were professionally adapted from body figure drawings created by Collins [44] in order to have African-American features.

\subsubsection{Attribution Task.}

Seven pairs of polar-opposite adjectives were read to the children. They were asked to point to the body figure that was associated with the adjectives, or choose an option "I don't know" when asked to assign the adjectives. The seven pairs of attributes were adapted from a list used previously used in body build stereotype research $[45,26,29]$ for both cultural and developmental sensitivity based on the recommendations of several early childhood experts. The seven pairs of attributes were as follows: knows a lot/ stupid; feels good/ feels bad; has lots of friends/ has no friends; nice/ mean; happy/sad; doesn't get made fun of/ gets made fun of a lot; good looking or pretty/ ugly. In addition to the attributes, children were asked which figure they would most like to play with/ not like to play with, as well as who they most would like to look like/ would not want to look like.

\subsubsection{Body Mass Index (BMI)}

Body Mass Index (BMI) was calculated by dividing weight in kilograms by the square of height in meters $(\mathrm{kg} / \mathrm{m} 2)$. Height and weight was measured twice, using a Seca 225 Height Rod stadiometer, and rounded to the nearest $0.1 \mathrm{~kg}$ and $\mathrm{cm}$, respectively. Height and weight were measured by a trained graduate student in exercise science.

\section{Results}

Data were analyzed in two ways, using Statistical Package for the Social Sciences (SPSS) version 19. First, a total number of attributes, either positive or negative, were calculated for each figure. In this way, possible differences between the number of negative or positive attributes for each figure could be calculated. The resultsindicated a significant interaction between age and which body figure was attributed negative attributes $\mathrm{F}(4,24)=2.59, \mathrm{p}<.05$, $\eta 2=.23$. Further explorations of the interaction revealed that 
three year-olds do not attribute negative traits differentially according to body types, while four and five year olds assigned significantly more negative attributes to the obese figure, than to the average or thin figure. The analysis reflecting differences among positive attributes was not conducted because 13 of the 24 participants did not complete the task, choosing the "I don't know option on at least one of the attributes." Interestingly, the same children rarely had difficulty assigning negative attributes based on body size.

The second method in which the data were analyzed was the creation of a continuous anti-fat bias score based on whether or not the participant chose the obese figure for each of the seven negative attributes in addition to the two questions about which child they "would not want to play with" or "would not want to look like." More specifically, for each negative attribute (e.g., ugly, mean, not want to play with), if a child chose the obese figure, the child was given a score of 1 . If the child chose either the average or thin figure for the negative attribute, the child received a score of 0 . The scores were then summed to create the anti-fat bias with possible scores ranging from 0 to 9 . The child's body mass index (BMI), a common measurement of obesity, and age were regressed on the anti-fat score using a linear multiple regression analysis. The analysis resulted in a significant linear model $\mathrm{F}(2,18)=5.49, \mathrm{p}<.05, \mathrm{R} 2=.41$. Results revealed that BMI did not significantly contribute to anti-fat biases $\mathrm{t}=1.17, \mathrm{p}>.05$, while age significantly contributes to anti-fat biases $\mathrm{t}=3.29, \mathrm{p}<.05$, with the older children reporting stronger anti-fat biases.

\section{Discussion}

The results of the present study are consistent with previous research indicating that the social stigmatization of obesity is present in young children [29,30]. However, the findings represent the important beginnings of understanding anti-fat attitudes of minority children who are at greater risk of obesity. As such, the finding that African American children for economically disadvantaged homes begin to clearly harbor anti-fat attitudes by age 4 , is unique and compelling. Further, the observation that nearly $50 \%$ of participants would not attribute positive characteristics based on body type, but had no difficulty attributing negative characteristics based on body type, represents a burgeoning area for future research on weight bias. This form of negative attribution theory likely represents a social ideology that allows individuals to account for negative life circumstances of others through negative evaluations and attributions [8]. Future research would benefit from investigating when children from different backgrounds begin to express bias based on body type, and why negative attributes are more easily assigned than positive qualities. Further, little is known on how the anti-fat attitudes of preschoolers may influence their social behavior. Studies in the preschool classroom to investigate how attitudes may be linked to behavior are warranted.
While the current study represents important progress in the understanding the development of anti-fat attitudes in minority children, it is not without limitations. First, because the sample size is small, generalizations to the population are limited. Additionally, the current design of the study is cross-sectional in nature and conclusions about the development of anti-fat attitudes are less confident than with a longitudinal design. However, the findings from the current exploratory study may be important for informing prevention strategies concerning the social prejudice against obese individuals. Such strategies may be most successful at a very early age, before the anti-fat biases become more prevalent.

\section{REFERENCES}

[1] Flegal, K., Carroll, M., Kit, B., \& Ogden, C. (2012). Prevalence of obesity and trends in the distribution of body mass index among us adults, 1999-2010. JAMA, 307(5), 491-497.

[2] Dehgan, M., Akhtar-Danesh, N., \& Merchant, A. (2005). Childhood obesity, prevalence and prevention. Nutrition Journal , 4(24), doi: 10.1186/1475-2891-4-24

[3] Anderson, S., \& Whitaker, R. (2009). Prevalence of obesity among us preschool children in different racial and ethnic groups. Arch Pediatr Adolesc Med, 163(4), 344-348. doi: 10.1001/archpediatrics.2009.18.

[4] Wang, Y., Gortmaker, S., \& Taveras, E. (2011). Trends and racial/ethnic disparities in severe obesity among us children and adolescents, 1976-2006. International Journal of Pediatric Obesity, 6(1), 12-20. doi: $10.3109 / 17477161003587774$

[5] Wang, S., Brownell, K., \& Wadden, T. (2004). The influence of the stigma of obesity on overweight individuals. International Journal of Pediatric Obesity, 28, 1333-1337. doi: 10.1038/sj.ijo.0802730

[6] Sikorski, C., Luppa, M., Brahler, E., Konig, H., \& Riedel-Heller, S. (2012). Obese children, adults and senior citizens in the eyes of the general public: Results of a representative study on stigma and causation of obesity . Public Library of Science, 7(10), doi: 10.1371/journal.pone.0046924

[7] Sikorski, C., Luppa, M., Kaiser, M., Glaesmer, H., Schomerus, G., Konig, H., \& Riedel-Heller, S. (2011). The stigma of obesity in the general public and its implications for public health - a systematic review. BMC Public Health, 11(661), doi: 10.1186/1471-2458-11-661

[8] Crandall, C. (1994). Prejudice against fat people: ideology and self-interest. Journal of Personality and Social Psychology, 66(5), 882-894.

[9] Puhl, R., Andreyeva, T., \& Brownell, K. (2008). Perceptions of weight discrimination: prevalence and comparison to race and gender discrimination in america. International Journal of Pediatric Obesity, 32, 992-1000. doi: 10.1038/ijo.2008.22

[10] Latner, J., O'Brien, K., Durso, L., Brinkman, L., \& 
MacDonald, T. (2008). Weighing obesity stigma: the relative strength of different forms of bias. International of Obesity, 32(7), 1145-1152. doi: 10.1038/ijo.2008.53

[11] Rogge, M., Greenwald, M., \& Golden, A. (2004). Obesity, stigma, and civilized oppression. Advances in Nursing Science, 27(4), 301-315.

[12] Puhl, R., \& Heuer, C. (2009). The stigma of obesity: A review and update. Obesity, 17(5), 941-964. doi: $10.1038 /$ oby. 2008.636

[13] Weiner, B., Perry, R., \& Magnussen, J. (1988). An attributional analysis of reactions to stigmas. Journal of Personality and Social Psychology, 55(5), 738-748. doi: 10.1037/0022-3514.55.5.738

[14] DeJong, W. (1980). The stigma of obesity: The consequences of naive assumptions concerning the causes of physical deviance. Journal of Health and Social Behavior, $21,75-87$

[15] DeJong, W. (1993). Obesity as a characterological stigma: the issue of responsibility and judgments of task performance. Psychological Reports, 73(3), 963-970.

[16] Crandall, C., \& Moriarty, D. (1995). Physical illness stigma and social rejection. British Journal of Social Psychology, 34(1), 67-83.

[17] Puhl, R., \& Brownell, K. (2001). Bias, discrimination, and obesity. Obesity Research, 9(12), 788-805.

[18] Agerstrom, J., \& Rooth, D. (2011). The role of automatic obesity stereotypes in real hiring discrimination. Journal of Applied Psychology, 96(4), 790-805.

[19] Jeffrey, C., \& Kitto, S. (2006). Struggling to care: Nurses' perceptions of caring for obese patients in an Australian bariatric ward . Health Sociology Review, 15(1), 71-83. doi: 10.5172/hesr.2006.15.1.71

[20] Wolf, A. (2002). Economic outcomes of the obese patient. Obesity, 10(11), 58-62. doi: 10.1038/oby.2002.191

[21] O'Brien, K., Hunter, J., \& Banks, M. (2007). Implicit anti-fat bias in physical educators: Physical attributes, ideology and socialization. International Journal of Obesity, 31, 308-314.

[22] Percy, S., \& Eccleston, C. (2011). Medical student bias and care recommendations for an obese versus non-obese virtual patient. International Journal of Obesity, 35, 728-735. doi: 10.1038/ijo.2010.173

[23] Schwartz, M., Chambliss, H., Brownell, K., Blair, S.,\& Billington, C. (2003). Weight bias among health professionals specializing in obesity. Obesity, 11(9), 1033-1039. doi: 10.1038/oby.2003.142

[24] Teachman, B., Gapinski, K., Brownell, K., Rawlins, M., \& Jeyaram, S. (2003). Demonstrations of implicit anti-fat bias: The impact of providing causal information and evoking empathy. Health Psychology, 22(1), 68-78. doi: 10.1037/0278-6133.22.1.68

[25] Carpenter, K., Hasin, D., Allison, D., \& Faith, M. (2000). Relationships between obesity and dsm-iv major depressive disorder, suicide ideation, and suicide attempts: results from a general population study. American Journal of Public Health, 90(2), 251-257.
[26] Brylinksky, J., \& Moore, J. (1994). The identification of body build stereotypes in young children. Educational Psychology, 28(2), 170-181.

[27] Latner, J., \& Stunkard, A. (2003). Getting worse: The stigmatization of obese children. Obesity, 11(3), 452-456. doi: 10.1038/oby.2003.61

[28] Rand, C., \& Resnick, J. (2000). The "good enough" body size as judged by people of varying age and weight. Obesity, 8(4), 309-316. doi: 10.1038/oby.2000.37

[29] Cramer, P., \& Steinwert, T. (1998). Thin is good, fat is bad: How early does it begin?. Journal of Applied Developmental Psychology, 19(3), 429-451. doi: 10.1016/S0193-3973(99)80049-5

[30] Musher-Eizenman, D., Holub, S., Miller, A., Goldstein, S., \& Edwards-Leeper, L. (2004). Body size stigmatization in preschool children: The role of control attributions. Journal of Pediatric Psychology, 29(8), 613-620. doi: 10.1093/jpepsy/jsh063

[31] Puhl, R., \& Latner, J. (2007). Stigma, obesity, and the health of the nation's children. Psychological Bulletin-American Psychological Association, 133(4), 557-580. doi: 10.1037/0033-2909.133.4.557

[32] Neumark-Sztainer, D., Story, M., \& Faibisch, L. (1998). Perceived stigmatization among overweight african-american and caucasian adolescent girls. Journal of Adolescent Health, 23(5), 264-270. doi: 10.1016/S1054-139X(98)00044-5

[33] Hansson, L., Karnehed, N., Tynelius, P., \& Rasmussen, F. (2009). Prejudice against obesity among 10-year-olds: a nationwide population-based study. Acta Paediatrica, 98(7), 1176-1182. doi: 10.1111/j.1651-2227.2009.01305.x

[34] Strauss, R., \& Pollack, H. (2003). Social marginalization of overweight children. JAMA, 157(8), 746-752. doi: 10.1001/archpedi.157.8.746

[35] Holub, S. (2008). Individual differences in the anti-fat attitudes of preschool-children: The importance of perceived body size. Body Image, 5(3), 317-321. doi: 10.1016/j.bodyim.2008.03.003

[36] Meers, M., Koball, A., Oehlhof, M., Laurene, K., \& Musher-Eizenman, D. (2011). Assessing anti-fat bias in preschoolers: A comparison of a computer generated line-drawn figure array and photographic figure array. Body Image, 8(3), 293-296.

[37] Shavers-Hornaday., Lynch, , Bermeister, , \& Torner, (1997). Why are african americans under - represented in medical research studies? impediments to participation. Ethnicity and Health, 2(1-2), 31-45. doi: 10.1080/13557858.1997.9961813

[38] Wendler, D., Kington, R., Madans, J., Van Wye, G., Christ-Schmidt, H., Pratt, L., Brawley, O., \& Gross, C. (2005). Are racial and ethnic minorities less willing to participate in health research?. Public Library of Science, 3(2), doi: 10.1371/journal.pmed.0030019

[39] Harris, Y., Gorelick, P., Samuels, P., \& Bempong, I. (1996). Why african americans may not be participating in clinical trials. Journal of the National Medical Association, 88(10), 630-634.

[40] Lovejoy, M. (2001). Disturbances in the social body: 
Differences in body image and eating problems among african american and white women. Gender and Society, 15(2), 239-261. doi: 10.1177/089124301015002005

[41] Rubin, L., Fitts, M., \& Becker, A. (2003). Whatever feels good in my soul: Body ethics and aesthetics among african american and latina women. Culture, medicine and psychiatry, 27, 49-75.

[42] Parker, S., Nichter, M., Nichter, M., Vuckovic, N., Sims, C., \& Ritenbaugh, C. (1995). Body image and weight concerns among african american and white adolescent females: Differences that make a difference. Human Organization, 54(2), 103-114.
[43] Puhl, R., Luedicke, J., \& Heuer, C. (2011). Weight-based victimization toward overweight adolescents: Observations and reactions of peers. Journal of School Health, 81(11), 696-703. doi: 10.1111/j.1746-1561.2011.00646.x

[44] Collins, M. E. (1991). Body figure perceptions and preferences among preadolescent children. International Journal of Eating Disorders, 10(2), 199-208. doi: 10.1002/1098-108X(199103)10:2<199::AID-EAT22601002 09>3.0.CO;2-D

[45] Stager, S. F., \& Burke, P. J. (1982). a reexamination of body build stereotypes. Journal of Research in Personality, 16, 435-446. 